\title{
Sports injuries in athletes with disabilities: wheelchair racing
}

\author{
D Taylor ${ }^{1}$ and T Williams ${ }^{2}$ \\ ${ }^{1}$ Department of Human Sciences, ${ }^{2}$ Department of Physical Education, Sports Science and Recreation \\ Management, Loughborough University, Loughborough, Leicestershire, LE11 3TU, UK
}

This study investigates the incidence of sports injuries in athletes who participate in wheelchair racing in the UK. Wheelchair racing has been identified as one of the top 'injury risk' sports but little information is available as to the incidence or type of injury sustained by British athletes. A questionnaire was used to collect information about injuries sustained in the last 12 months. Members of the British Wheelchair Racing Association (BWRA) were sent questionnaires. Most subjects ( $72 \%)$ reported having at least one injury within the previous 12 months. Training variables such as the distance pushed per week (Mann-Whitney $\mathrm{U}=61, P>0.05$ ), the amount of speed training (Mann-Whitney $\mathrm{U}=110, P>0.05$ ), the number of weight training sessions (Mann-Whitney $U=26$, $P>0.05$ ) or the length of time the athlete had been involved in wheelchair racing (Mann-Whitney $\mathrm{U}=103, P>0.05$ ) were not associated with the occurrence of an injury. Overuse injuries were common and recurred more often than other types of injuries $\left(\chi^{2}=3.95, P<0.05\right)$. Those athletes with recurring injuries also tended to be those who restarted training before they were pain-free from their injury $\left(\chi^{2}=5.31, P<0.05\right)$. There appears to be a link between overuse injuries, the presence of pain during training and the recurrence of injuries. A lack of knowledge about sports injuries, what causes them and what to do following an injury may contribute to the high incidence of overuse injuries in this group of athletes.

Keywords: wheelchair racing; sports injuries; overuse

\section{Introduction}

An increasing number of people with disabilities are participating in sport. ${ }^{1,2}$ Whilst athletes with disabilities may not be injured any more often than able bodied athletes, ${ }^{3}$ the types of injuries they sustain may be specific to their disabilities and sport. ${ }^{4}$ Research into the prevalence, incidence, causes and treatment of sports injuries in able bodied athletes is abundant; this is not the case for athletes with disabilities. ${ }^{1,5}$

Curtis ${ }^{6}$ investigated the number and types of injuries sustained by a variety of disabled sports people, including road racers, track and field athletes, basketball players and swimmers. It appeared that most $(72 \%)$ of the responding athletes reported at least one injury during their time of participation in sports. The most prevalent type of injury reported was soft-tissue injury $(33 \%)$. Few athletes reported seeking medical help. There were no relationships between age, sex or training patterns and the number of injuries reported. Disability type was not associated with the number of injuries reported. Ferrara ${ }^{7}$ reported that $32 \%$ of his subjects had a sports injury during the study period. It is difficult to compare the results of the study as they are based over different time periods.

Ferrara $^{2}$ investigated the incidence and type of injury sustained by elite wheelchair sports athletes (track and field athletes and swimmers). Of the 19 subjects that completed his study there were 50 injuries reported. Fifty-seven per cent of the injuries involved the wrist, hand and fingers and $31 \%$ involved the shoulder girdle.

Van Melchen ${ }^{8}$ suggests that the prevention of sports injuries should focus on changing the behaviour of athletes by educating them. This education should focus on the importance of complete rehabilitation, the early recognition of overuse and on the provision of training guidelines. However, to be able to prescribe preventative measures one needs to know the causes and types of injuries that are sustained by athletes.

It was felt that there was a need for a sport specific study into injury patterns. This study deals with wheelchair racers, one of the top five 'injury risk' sports. ${ }^{4,6,9}$ The purpose of this study was to obtain data about (1) training activities and (2) number and types of injuries sustained by British wheelchair racers in a 12 month period.

\section{Methods}

A questionnaire was developed, the first section of which utilised many of the same variables used by Hedrick et $a l^{10}$ and Watanabe et $a l^{11}$ and included age; body weight; nature of impairment; years of experience in wheelchair racing. The second section dealt with training issues, such as: the average number of weekly 
pushing workouts (in each of the periods of JanuaryMarch, April-June, July-September and OctoberDecember); average number of minutes per pushing session; average pushing distance per week. The third section dealt with information sources and asked questions about which sources wheelchair racers consulted for information about aspects of their sport. The fourth section dealt with sports injuries experienced in the last 12 months. Subjects were asked to report: the site of injury; whether it prevented training or racing and for how long; whether medical help was sought; whether any pain had gone when training or racing started again; how many times the injury had recurred in the last 12 months; and how the injury was sustained. An injury was defined as pain in any part of the body that affected or prevented the athlete from training or competing for at least 1 day. It is a broad definition aimed at identifying injuries that were traumatic in origin (such as falls from the chair) and those that arose as a result of repetitive actions. This definition of an injury is similar to that used by Ferrara. ${ }^{7}$

The questionnaire items were constructed in collaboration with the British Wheelchair Racing Association (BWRA) and draft questionnaires were administered to four wheelchair racers, who were then interviewed to identify and correct ambiguous items. The questionnaire, together with a stamped addressed envelope, was mailed by the BWRA with the Association's newsletter. The newsletter editor had placed an item in the newsletter asking for cooperation. Telephone follow-up procedures were used to improve the response rate. The results presented here are those concerning sports injuries and training activities.

\section{Results}

Fifty three members of the BWRA completed the questionnaire. This represents an estimated $58 \%$ of the total number of wheelchair racers in the United Kingdom who participate in at least one race per year. It is estimated that it represents $98 \%$ of the racers who regularly competed in the BWRA Grand Prix Races in 1992. A test-retest procedure was carried out on a subsection of the sample. There was an $84 \%$ agreement rate on the sports injuries section and an agreement rate of $86 \%$ on the remainder of the questionnaire.

Seventy seven per cent (41) of the respondents were men and $23 \%$ (12) were women. Fifty nine per cent of the respondents were aged between 25 and 39 years. The commonest impairment was spinal cord injury $(56 \%)$, followed by spina bifida $(28 \%)$. Three years was the median time that the subjects had been participating in wheelchair racing, with an interquartile range of $1-5.75$ years.

Twenty eight per cent (17) of subjects reported that they had not had any injuries in the last year. Seventy two per cent (38) of the subjects reported having experienced at least one injury in the last year. Forty four separate injuries were reported. Twenty one of these injuries had occurred on one occasion only, the other 23 injuries occurred on more than one occasion in individual athletes (Figure 1). The most commonly injured body part was the hand and wrist $(27 \%)$ followed closely by the shoulder and upper arm (25\%).

The subjects were divided into elite and non-elite wheelchair racers. Twenty one of the athletes (four women and 17 men) were classified as elite by the BWRA, either because of their membership of the British Paralympic team or their racing performances. The remaining 32 racers (eight women and 24 men) were considered non-elite and of these four were juniors (under 16 years of age).

The data were investigated to see if the number and the frequency at which the same injury recurs in the same athlete was different in elite and non-elite athletes. There appeared to be no differences in the elite and non-elite athletes in the number of injuries they reported $\left(\chi^{2}=0.25, P>0.05\right)$ and whether or not the same injury recurred $\left(\chi^{2}=1.23, P>0.05\right)$. As there was no difference between the injury status of elite and non-elite racers the data were combined.

Subjects were asked to describe how each injury occurred. Content analysis was used to place the injury description into one of three categories, similar to those categories used by Booth: ${ }^{5}$ (1) overuse injury, (2) traumatic injury and (3) other (Table 1). The injury could not be categorised in five cases.

Most injuries (71\%) prevented the subjects from training, rather than moderating training. Those subjects who stopped training had a median time off training of 14 days. There was a large variation, ranging from 1 day to 1 year. In about half of the cases of an injury being reported medical help was sought (45\%). In most of the other cases of injury medical help was

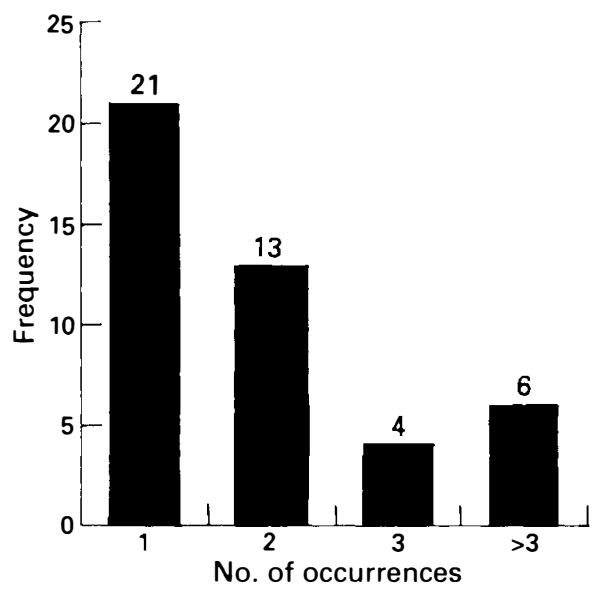

Figure 1 The frequency of injury occurrences

Table 1 Counts and per cents in each injury category

\begin{tabular}{lcc}
\hline Injury category & Count & Per cent \\
\hline Overuse & 23 & $52 \%$ \\
Traumatic & 7 & $16 \%$ \\
Other & 9 & $21 \%$ \\
Unclassified & 5 & $11 \%$ \\
\hline
\end{tabular}


not sought $(52 \%)$. In just under half the cases of injury the subjects pain had not disappeared before they re-started training $(43 \%)$, whereas in $55 \%$ of the injury cases the subject had no pain when they recommenced training. There was no difference in the number of subjects seeking medical help in any of the injury categories; people were equally likely to seek medical help if the injury was overuse, traumatic or other $\left(\chi^{2}=0.9, P>0.05\right)$.

The injuries that were categorised in the 'traumatic' or 'other' categories were grouped together and compared with the 'overuse' group. The number of times athletes complained of the same injury in the 12 month period was counted in each of the groups. A $\chi^{2}$ test was used to assess whether a greater proportion of overuse injuries occurred more than once in the 12 month period compared to all the other injuries. The $\chi^{2}$ test was significant at the 0.05 level $\left(\chi^{2}=3.95\right)$.

The incidence of injury that had been reported as re-occurring (group B) was compared to those that had been reported as occurring once in the athlete (group A). The two groups were compared to look for differences in whether pain from the injury had gone before training was re-started (Table 2). Those subjects in group B tended to re-start training before the pain from their injury had gone. $\chi^{2}$ was significant at the 0.05 level $\left(\chi^{2}=5.31\right)$.

The question was then asked about whether there were any differences in the types of injuries that occurred in group A and B. Because the sample was small, those injuries in the traumatic category were combined with those in the other category to allow for statistical analysis (Table 3). A significantly greater proportion of the injuries in group $\mathrm{B}$ were overuse injuries $\left(\chi^{2}=3.95, P<0.05\right)$.

Training activities were examined to see if there was any relationship with the occurrence of injury.

Table 2 Comparison of groups $\mathrm{A}$ and $\mathrm{B}$ : the presence of pain at the re-start of training

\begin{tabular}{lccc}
\hline $\begin{array}{l}\text { Pain present on } \\
\text { re-starting training }\end{array}$ & $\begin{array}{c}\text { One off } \\
\text { injury }(A)\end{array}$ & $\begin{array}{l}\text { Recurring } \\
\text { injury }(B)\end{array}$ & Total \\
\hline Yes & 8 & 14 & 22 \\
No & 15 & 6 & 21 \\
Total & 23 & 20 & 43 \\
\hline
\end{tabular}

1 missing data point - unclassifiable

Table 3 Frequency of occurrence of injury by category over the 12 month period

\begin{tabular}{lccc}
\hline $\begin{array}{l}\text { Frequency of } \\
\text { occurrence }\end{array}$ & Overuse & $\begin{array}{c}\text { Traumatic and } \\
\text { other }\end{array}$ & Total \\
\hline One off injury (A) & 7 & 10 & 17 \\
Recurring injury (B) & 16 & 6 & 22 \\
Total & 23 & 16 & 39 \\
\hline
\end{tabular}

5 missing data points - unclassifiable
There was no relationship with the number of miles pushed in training per year (Mann-Whitney $U=61$, $P>0.05$ ), the amount of speed training (MannWhitney $U=110, P>0.05$ ) the number of weight training sessions (Mann-Whitney $U=26, P>0.05$ ) or the length of time the athlete had been involved in wheelchair racing (Mann-Whitney $\mathrm{U}=103$, $P>0.05)$.

The athletes who had a structured training programme were compared with those who did not have such a programme to see if there were any differences in the injury occurrence. Twenty one subjects had a structured training programme and 32 did not. There was no difference in the occurrence of injuries $\left(\chi^{2}=0.001, P>0.05\right)$. The same comparison was performed, this time dividing the sample into those who had a coach and those who did not. Again, there was no difference in the injury occurrence $\left(\chi^{2}=0.2\right.$, $P>0.05)$.

\section{Conclusions and discussion}

This study provides subjective, historical information from wheelchair racers. It is not a diagnostic or injury register, but it is a first step in understanding the nature of sports injuries in British sports people with disabilities. The sample was biased in that all the subjects belonged to the BWRA and raced in the BWRA's grand prix races but it is thought that this represents the majority of active wheelchair racers. When compared to athletes in other studies ${ }^{2,7}$ this group were relatively inexperienced as far as the number of years they had been competing.

There appeared to be no differences in the elite and non-elite athletes in the number of injuries they reported and whether or not the same injury recurred. Most injuries prevented the subjects from training and in about half of the cases medical help was sought; this differs greatly from the results of Ferrara's study ${ }^{7}$ where over four fifths of the subjects sought medical help. People were equally likely to seek medical help if the injury was overuse, traumatic or had other causes.

It appeared that the incidence or type of injury was not influenced by such training activities as the amount of speed training, weight training or the distance pushed in a training session. This finding was unexpected as it is often cited that training programmes can affect the number of injuries suffered by athletes. ${ }^{12-14}$

There was a relatively high incidence of reports of overuse injury, and it appeared that these overuse injuries were likely to recur within a 12 month period. Those athletes who reported recurring injuries tended to re-start their training before the pain from their injury had gone. It may be that these injuries recur because they have not fully healed before they are subjected to the stresses of further training. Alternatively it may be that the nature of the overuse injuries is such that they will recur whether or not substantial rest is given. The data suggest that there is a link between overuse injuries, re-starting training before pain has disappeared and the rate of recurrence of the injury. 
Further research needs to be undertaken to clarify this relationship. The answers given by the athletes seemed to highlight their lack of knowledge of sports injuries, what causes them and what to do subsequent to injury. The level of knowledge about training regimes and sports injury prevention may account for the seemingly large proportion of athletes with overuse injuries.

\section{References}

1 Hoeberigs JH, Debets-Eggen HBL, Debets PML. Sports medical experiences from the International Flower Marathon for disabled wheelers. Am J Sports Med 1990; 18: 418-421.

2 Ferrara MS, Davis RW. Injuries to elite wheelchair athletes. Paraplegia 1990; 28: 335-341.

3 McCormick DP. Injuries in handicapped alpine ski racers. Physician Sportsmed 1985; 13: 93-97.

4 Bloomquist LE. Injuries to athletes with physical disabilities: prevention implications. Physician Sports Med 1986; 14: 97-105.

5 Booth DW. Athletes with disabilities. In: Harries M, Williams C, Stanish WD, Micheli LJ (eds). Oxford Textbook of Sports
Medicine. Oxford University Press: Oxford, UK.

6 Curtis AK, Dillon DA. Survey of wheelchair athletic injuries: common patterns and prevention. Paraplegia 1985; 23: 170-175.

7 Ferrara MS et al. The injury experiences of the competitive athlete with a disability: prevention implications. Med Sci Sports Exerc 1992; 24: 184-188.

8 Van Melchen W. Running injuries: A review of the epidemiological literature. Sports Med 1992; 14: 320-335.

9 Gayle GW, Muir JL. Roles of sportsmedicine and the spinal cord injured: A multidisciplinary relationship. Palaestra 1992; Spring: 51-56.

10 Hedrick BN, Morse MI, Figoni SF. Training practices of elite wheelchair roadracers. Adapt Phys Activ $Q$ 1988; 5: 140-153.

11 Watanabe KT et al. Training practices of athletes who participated in the National Wheelchair Athletic Association training camps. Adapt Phys Activ $Q$ 1992; 9: 249-260.

12 Ekstrand J, Gillquist $\mathrm{J}$. The frequency of muscle tightness and injuries in soccer players. Am J Sports Med 1982; 10: 75-78.

13 Ekstrand $\mathrm{J}$ et al. Incidence of soccer injuries and their relation to training and team success. Am J Sports Med 1983; 11: 63-67.

14 Blair SE, Kohl HW, Goodyear NN. Rates and risks for running and exercise injuries: Studies in three populations. Res $Q$ Exerc Sport 1987; 58: 221-228. 